\title{
ASSISTENCIA DE ENFERMAGEM A PACIENTES COM MANIFESTAÇÕES DE CONFUSÃO MENTAL
}

\author{
Marina Borges Teixeira* \\ Hideko Takeuchi Forcella*
}

TEIXEIRA, M. B.; FORCELLA, H. T. Assistência de enfermagem a pacientes com manifestações de confusão mental. Rev. Esc. Enf. USP, São Paulo, 15(1):73-78, 1981.

As autoras apresentam algumas noções básicas sobre pacientes com confusão mental e $a$ assistência de enfermagem a eles prestada.

\section{INTRODUÇÃO}

Confusão mental, segundo POROT (1977), é uma síndrome mental generalizada, quase sempre de começo agudo, caracterizada por dissolução mais ou menos completa da consciência, dificuldade na ideação, lentidão das percepções e dos processos de orientação e identificação, entremeada com períodos de lucidez.

Suas causas são quase sempre tóxico-infecciosas, podendo também decorrer de trauma de origens diversas (física ou psicológica), acidente vascular cerebral, arteriosclerose cerebral, neoplasias e doenças de causa desconhecida como a esclerose múltipla, coréia de Huntington e doença de Alzheimer. Em geral surge em indivíduos com certa predisposição constitucional; pode surgir também como conseqüência de um quadro de estafa ou, ainda, de mau estado físico geral que predispõe o indivíduo a infecções. Portanto, pacientes portadores de doenças infecciosas ou qualquer outro quadro orgânico, bem como recém-operados, podem apresentar, de um momento para outro, perplexidade ansiosa, agitação intensa associada ou não a alucinações, idéias delirantes, delírio onírico, ansiedade, desorientação auto e alopsíquica, obnubilação da consciência e defenestração que são as alterações mais típicas de quadro confusional.

EY et alii (1979) e LôO \& LôO (1971) afirmam que, em geral, os quadros confusionais agudos apresentam remissão total, enquanto os crônicos, se bem que tratáveis, sofrem recidivas de freqüência variável. Isto pode ser notado nos quadros confusionais que ocorrem nos pacientes idosos, quadros estes geralmente decorrentes de arteriosclerose. $O$ quadro confusional pode ou não ser reversível, dependendo da forma como se apresenta, agudo ou crônico.

Crianças podem ter, dependendo do fator desencadeante da confusão mental como seqüela grave, deficiência intelectual ou ainda alterações motoras, se houver lesões irreversíveis no sistema nervoso. É importante diagnosticar, no mais breve periodo de tempo possivel, a causa do quadro confusional, para prevenção de seqüelas irreversíveis.

* Professor Assistente da disciplina Enfermagem Psiquiátrica da EEUSP. Mestre em Enfermagem. 


\section{ASSISTENCIA DE ENFERMAGEM}

A assistência de enfermagem, assim como o tratamento médico, difere de paciente para paciente, respeitadas as manifestações de comportamento e a idade do paciente.

A impressão causada pela expressão facial do paciente confuso é de aparvalhamento, medo e perplexidade. Olha as pessoas com os olhos bem abertos como se indagando sobre o que está ocorrendo, onde está ou quem é a pessoa para quem está olhando. Ȧs vezes apresenta lentidão de movimentos, ou, ao contrário, movimenta-se sem parar, fala sem cessar de forma ininteligível ou parece não saber ou entender o significado das palavras. Outras vezes fala em tom de voz baixo e, a vezes, permanece em mutismo por longo tempo.

Em geral não cuida de sua higiene e aparência, nem denota preocupação em se alimentar. Não consegue situar-se no tempo e no espaço, tendo dificuldade em localizar seu próprio leito e em identificar pessoas e objetos que o rodeiam. Não se recorda de fatos e orientações recentes, mas consegue lembrar-se de eventos remotos, isto faz com que o paciente tenha dificuldade em seguir as rotinas da instituição.

Por outro lado, pode tornar-se inquieto, gritar, correr, rasgar suas vestes, agredir as pessoas ou a si mesmo, referir ver bichos ou cenas terrorificas, demonstrando, por sua expressão facial, pavor intenso.

Pode apresentar inúmeros problemas somáticos, dependendo de sua condição física. São mais comuns: hipertermia, língua saburrosa, emagrecimento, palidez e lábios ressecados.

Ass vezes, o quadiro é difícil de ser identificado, pois o paciente pode não demonstrar os sintomas permanecendo quieto, e somente por meio de observação acurada do seu comportamento é que se percebem desorientação e dificuldade de cuidar de si próprio. Tendo por base essa observação, o enfermeiro terá elementos para traçar seu plano de assistência, iniciando pela identificação dos problemas, tanto do paciente como do pessoal que o assiste.

Nos momentos de lucidez, o paciente pode apresentar medo, ansiedade e insegurança, porque não consegue distinguir se o que está ocorrendo é real ou não.

Outros problemas que o paciente pode apresentar são: dificuldade para entender e memorizar as orientações recebidas; irritação provocada por sua dependência, decorrente de suas condições físicas e mentais; e sensações de mal estar e dor, ocasionadas pelos problemas somático que podem ter provocado aparecimento do quadro confusional ou que surgiram como consequiência deste.

0 primeiro problema que o enfermeiro encontra, ao lidar com o paciente com quadro confusional, é a não aceitação das manifestações de comportamento deste por todos os membros da equipe de enfermagem, uma vez que o paciente, nos períodos de lucidez, comporta-se como um indivíduo aparentemente normal.

Manter conversação com o paciente torna-se difícil quando o conteúdo do seu pensamento é ilógico e incoerente e freqüentemente ininteligível, o que provoca irritação no pessoal que o atende. 
Por ter deficiências de orientação e memória, o paciente não segue as rotinas, o que também causa problemas, tanto para equipe de enfermagem como para os demais pacientes.

A dependência do paciente provocada pela dificuldade em cuidar de sua aparência, higiene e em alimentar-se, é também considerada problema, uma vez que isto irrita os membros da equipe e conseqüentemente provoca rejeição do pacicnte.

As manifestações de agitação requerem controle e estas manifestações, bem como o seu controle provocam ansiedade no pessoal de enfermagem e nos demais pacientes.

Paralelamente aos problemas decorrentes do quadro psíquico, não pode ser esquecida a responsabilidade que a equipe de enfermagem tem de evitar complicações e agravamento do quadro físico que gerou a doença, ou que surgiu como conseqüência desta.

O cansaço e a irritação dos membros da equipe de enfermagem motivadios por todos problemas já citados, acrescidos da necessidade de vigilância constante e a necessidade de ser evitada troca de funcionários, constituem sérios problemas para a enfermagem.

Ao assistir o paciente com manifestação de comportamento decorrente de confusão mental, o enfermeiro deve, por tanto, ter como objetivos primordiais mantê-lo orientado e proporcionar-lhe ambiente no qual se sinta seguro.

Cada vez que o enfermeiro for atendê-lo, deve apresentar-se e dizer o que veio fazer. Tratar sempre o paciente pelo nome, não se esquecendo de título como Doutor, Professor, se for o caso. Essa atenção direta deve ser mantida até que o paciente demonstre estar retendo na memória os eventos recentes. Ao conversar, o enfermeiro deve sempre referir-se a fatos ou assuntos concretos e familiares ao paciente, usando frases curtas e diretas; deve aguardar a resposta do paciente e, caso seja necessário, repetir a pergunta da mesma forma como foi elaborada anteriormente; deve esforçar-se por entender o que o paciente está tentando transmitir e, caso não o consiga, deve procurar ajudá-lo a expressar suas idéias.

São cuidados que visam manter o paciente orientado: conservá-lo no mesmo quarto, sem mudar a posição do mobiliário; providenciar calendário, relógio, óculos, aparelho de audição e outras próteses necessárias; prover uma seqüência de atividades diárias constantes e, estar alerta para que o paciente seja assistido pelos mesmos funcionários. Quando o paciente não consegue fixar as orientações, estas devem ser repetidas pelo enfermeiro com utilização das mesmas palavras, sem demonstrar irritação. Quando o paciente apresentar falsos reconhecimentos, ele deve ser esclarecido sobre a situação real na qual se encontra.

Às vezes, a presença de uma pessoa da família do paciente, devidamente orientada, pode ser benéfica para sua recuperação, ajudando-o a manter-se orientado auto e alopsiquicamente.

Todos que cuidam do paciente devem estar atentos para que não sejam feitos comentários sobre ele, na sua presença, uma vez que o paciente apresenta períodos de lucidez, ficando ansioso ao perceber que estão falando dele. 
O enfermeiro dreve programar as atividades junto ao paciente, a fim de que ele receba estímulos de forma equilibrada. Portanto, os cuidados do paciente devem ser distribuídos equitativamente durante as horas do dia, para evitar que o paciente sofra excesso ou falta de estímulos.

Oferecer apoio, demonstrar interesse real em ajudá-lo, manter-se calma e com humor estável são contribuições para a melhora do paciente. $O$ controle da ansiedade deste é importantíssimo tanto quando ele está agitado como quando, já em período de remissão dos sintomas, ele tenta lembrar-se do que aconteceu quando esteve com quadro confusional, pois a amnésia lacunar não permite que ele se lembre. Por esta razão não se deve fazer comentários ou perguntar a respeito de suas manifestações de comportamento apresentadas durante o período confusional.

Caso o paciente apresente alucinações, ilusões ou idéias delirantes, o enfermeiro deve permanecer a seu lado até que sua ansiedade ou agitação diminuam; e deve procurar mantê-lo na realidade pela utilização de assuntos e ocupações concretas e, afirmar que acredita que ele esteja vendo ou ouvindo algo, mas que isto é produto de sua doença, quando ele pedir confirmação para seus sintomas.

As janelas devem atender as necessidades de iluminação e ventilação do ambiente e oferecer segurança à integridade física do paciente, devido à defenestração.

A iluminação da enfermaria deve ser de modo a não permitir jogo de luz e penumbra, uma vez que sombras estimulam a aparecimento de ilusões. $O$ enfermeiro deve, ainda, evitar que no ambiente do paciente existam ruídos muito agudos ou monótonos. Não pode discutir as idéias do paciente com ele e nem utilizálas para obter sua cooperação.

Os pacientes precisam ser constantemente observados e protegidos pelo pessoal de enfermagem, para evitar que sejam alvo de zombaria por parte dos demais.

Às vezes, dependendo de seu comportamento, o paciente deve ser isolado em ambiente com menos estímulos; neste caso, um funcionário deve permanecer junto a ele, procurando ocupá-lo, longe dos demais. Outras vezes, quando muito agitado, o paciente deve ser isolado em seu quarto, o que deve ser feito somente em último caso e pelo tempo estritamente necessário, pois essa medida pode ser extremamente prejudicial ao paciente que estiver sofrendo visões terrorificas.

Quando o paciente estiver acamado, é recomendado o uso de grades de proteção para evitar quedas, o que torna necessário manter maior vigilância, uma vez que ele, em diecorrência do quadro confusional, pode tentar pular a grade e sofrer algum acidente mais grave.

Oferecer apoio, permanecendo ao lado do paciente, usando técnicas de comunicação adequadas tranqüiliza o paciente. $O$ enfermeiro deve utilizar todas as medidas terapêuticas cabiveis para cada paciente em particular antes de solicitar a prescrição de medicamento tranqüilizante.

Em relação aos sintomas físicos, o paciente em geral não consegue explicar o que está sentindo. Deve-se ter como norma avaliar diariamente o seu estado 
físico providenciar banho mais vezes ao dia, em caso de hipertermia e sudorese, e propiciar mudança de decúbito e massagem de conforto sempre que necessário. Não esquecer da higiene oral com água bicarbonatada e outros cuidados básicos de enfermagem que visam o conforto do paciente.

Outro cuidado é verificar se o paciente está se alimentando e ingerindo líquidos em quantidade suficiente. Conhecer os seus hábitos alimentares, antes de vir ao hospital, ajuda o enfermeiro a providenciar dieta e hidratação adequadas.

À medida que o paciente vai se recuperando o enfermeiro com a utilização de técnicas de comunicação, vai fornecendo os elementos necessários para que ele analise realisticamente a experiência pela qual passou. Neste momento, é importantíssimo manter vigilância constante, porque essa análise pode ser muito penosa e provocar depressão no paciente levando-o, às vezes, até a tentativa de auto-climinação.

Por ocasião da alta, os familiares devem ser orientados quanto à probabilidade dele vir a sofrer novo quadro confusional, uma vez que já existe a chamadia predisposição, e também sobre como agir em relação ao problema da amnésia pós-confusional.

O paciente idoso, após o quadro confusional agudo, apresenta geralmente seqüelas que requerem tratamento especializado e ambiente adequado às suas condiçōes de vida. Caso seja necessário mantê-lo em casa, o membro da família que permanecer junto a ele deverá ser orientado a respeito de seu cuidado e a periodicamente, procurar o enfermeiro do hospital a fim de discutirem os progressos e problemas encontrados.

A criança, após a alta, poderá necessitar de orientação psicopedagógica, dependendo da seqüela que por ventura tenha restado. A família deve estar preparada para colaborar no seu tratamento e ser orientada sobre o modo de tratar a criança, evitar superproteção e facilitar seu reajustamento social.

Finalmente, em todos os casos, quer se trate de criança, adulto ou idoso, deve ser dada ênfase especial ao apoio aos familiares desses pacientes, desde o momento da internação até o periodo pós alta hospitalar. Isto possibilita diminuição da ansiedade dos familiares em relação ao paciente e favorece a integração deste nas atividades normais da vida diária.

TEIXEIRA, M. B. \& FORCELLA, H. T. Nursing care of confused patients. Rev. Esc. Enf. USP, São Paulo, 15(1):73-78, 1981.

The authors give some basic ideas about confused patients and the nursing care 'reded in such cases.

\section{REFERENGIAS BIBLJOGRAFICAS}

EY, H. et alii. Psicoses delirantes agudas. In: Tratado de psiquiatria. 5. ed. Barcelona, Toray Masson, 1979. cap. 6, p. $277 \cdot 93$.

LOO, P. \& LOO, H. El confuso. In:

Masson, 1971. cap. 4, p. 57-66.

POROT, A. Dicionário de psiquiatria. 3. ed. Barcelona, Labor, 1977. p. 276-8. 


\section{BIBLIOGRAFIA}

ADAMS, M. et alii. Psychological responses in critical care unities. Amer. J. Nurs., New York, 78(9): 1504-12, Sept. 1978.

ALMEIDA, E. M. \& CHAPMAN, A. H. The organic brain disorders. In: basis of psychiatric nursing. New York, Putnam's Sons, 1972. cap. 9, p. 190-229.

BETTA, J. C. Síndrome confusional. In: - Manual de psiquiatria. 5. ed. Buenos Aires, Albatros, 1972. cap. 6, p. 361-76.

CABRAL, C. A. Psicoses agudas. In: VIDAL, G.; BLEICHMAR, H.; USANDIVARAS, R. J. Enciclopédia de psiquiatría. Buenos Aires, Atheneu, 1977. p. 545-9.

DAVIDHIZAR, R. et alii. Recognizing and caring for the delirious patient. J. Psychiat. Nurs., New York, 16(5): 39-41, May 1978.

DODD, M. J. Assessing mental status. Amer J. Nurs., New York, 78(9): 1501-3, Sept. 1978.

FREEDMAN, A. M. et alif. Modern synopsis of comprehensive text book of psychiatry. II. 2. ed. Bal. timore, Willians \& Wilkens, 1977. cap. 18, p. 527-72.

H.FLING, C. K. et alii. Las psicosis. In: 2. Enfermería psiqufátrica. 2. ed. México, Interamericana, 1970 . cap. 12 , p. $215-20$.

KRONER, K. Dealing with the confused patient. Nursing, Marion, 11(9): 71-8, Nov. 1979.

MATHENEY, R. V. \& TOPALIS, M. Enfermería psiquiátrica. 5. ed. México, Interamericana, 1971. cap. 16 , p. $227-32$.

MERENESS, D. J. \& KARNOSH, L. J. Elementos de enfermería psiquiátrica. México, Prensa Médica Mexicana, 1964. p. 226-42.

ROBINSON, L. Patients who manifest symptions of psychiatric illness from organic causes. In: Psychiatric nursing as a human experience. Philadelphia, Saunders, 1972. cap. 13, p. 268.82. 